\title{
A estiva se diverte: organizações recreativas dos trabalhadores do porto carioca nas primeiras décadas do século XX
}

\author{
Erika Bastos Arantes ${ }^{[1]}$
}

\begin{abstract}
Resumo
Os primeiros anos do século são marcados por uma intensa atividade associativa dos trabalhadores. Essas associações, que podiam ser as mais diversas, certamente contribuíram de alguma forma para que os trabalhadores se identificassem como parte de um mesmo mundo e se reconhecessem como trabalhadores. No entanto, até bem pouco tempo a historiografia tendeu a observar apenas as associações que previam a luta operária, como os sindicatos. Analisando o caso dos trabalhadores do porto do Rio de janeiro, este artigo tem por objetivo investigar outras formas de organização operária, mais especificamente, as de cunho recreativo, como as sociedades carnavalescas, os clubes dançantes, ranchos etc. Buscarei aqui demonstrar a diversidade associativa daqueles trabalhadores, chamando a atenção para o fato de que identidades múltiplas - percebidas na diversidade das organizações - não impediam uma identidade de classe. Palavras-chave: negros; trabalhadores do porto; organizações carnavalescas.
\end{abstract}

Les dockers s'amuse: les organisations de loisirs des travailleurs du port de Rio de Janeiro dans les premières décennies du XXe siècle

\section{Resumen}

Les premières années du siècle sont marquées par une intense activité associative des travailleurs. Ces associations, qui étaient les plus diverses, certainement ont contribué en quelque sorte pour que les travailleurs s'identifient en tant que partie d'un même monde et se reconnaissent en tant que travailleurs. Néanmoins, jusquà tout récemment, l'historiographie a eu tendance à n'observer que les associations qui prévoyaient la lutte ouvrière, comme les syndicats. En analysant le cas des travailleurs du port de Rio de Janeiro, cet article a pour but d'analyser d'autres formes d'organisation ouvrière, plus spécifiquement celles dirigées à des activités de loisir, comme les sociétés qui organisent le carnaval, les clubs dansant, etc. Je chercherai à montrer ici la diversité associative de ces travailleurs en attirant l'attention sur le fait que des multiples identités - aperçues dans la diversité des organisations- n'empêchaient pas une unité de classe. Palabras claves: noirs, travailleurs du port, organisations liées au carnaval.

\section{The port workers have fun: recreative organization of workers in the port of Rio de Janeiro in the first decades of twentieth century}

\section{Abstract}

Abstract: The early years of the century are marked by intense associational activity among workers. These associations, which could be very different, certainly contributed in some way for workers to identify themselves as part of the same world and to recognize employees. However, until recently the historiography has tended to only observe associations which provided for the workers' struggle, as the unions. Analyzing the case of employees of the port of Rio de Janeiro, this article aims to examine other forms of organized labor, specifically the recreational nature, such as the carnival societies, dance clubs, etc. and ranches. I seek here to demonstrate the associative diversity of those workers, calling attention to the fact that multiple identities - the perceived diversity of organizations - did not prevent one class identity.

Keywords: port workers, carnival organizations.

Los estibadores se divierten: organizaciones recreativas de los trabajadores del puerto carioca en las primeras décadas del siglo XX

\section{Résumé}

Los primeros años del siglo XX son marcados por una intensa actividad en cuanto a la asociación de trabajadores se refiere. Dichas asociaciones, que podían ser de una gran diversidad, ciertamente contribuían de alguna forma para que los trabajadores se identificaran como parte de una misma realidad y se reconocieran como trabajadores. Sin embargo, hasta hace muy poco tiempo, la historiografía fue tendiente a observar solamente las asociaciones que visualizaban la luchara obrera, como la de los sindicatos. Analizando el caso de los trabajadores del puerto de Rio de Janiero, el presente artículo tiene como objetivo analizar otras formas de organización obrera, específicamente las de cuño recreativo, como las asociaciones carnavalescas, clubes de danzantes, y otras expresiones festivas culturales. Buscaré demostrar aquí la diversidad del tipo de asociaciones de aquellos trabajadores, poniendo especial atención en el hecho de que identidades múltiples - encontradas en la diversidad de organizaciones - no impedían una identidad de clase.

Mots-clés: negros, trabajadores del puerto, organizaciones carnavalescas. 


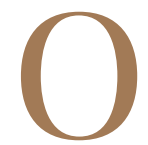

carnaval de 1911 deve ter sido um pouco mais animado que os outros para grande parte dos moradores da zona portuária e também de outros pontos da cidade. Um grupo de foliões seguiu um rancho que pela primeira vez saiu de sua sede na rua Barão de São Félix, nº 283, e desfilou pelas ruas do centro do Rio exibindo seu estandarte nas cores roxa e branca. À frente, o diretor de harmonia João Machado Guedes comandava os pandeiros, tamborins e bombos que marcavam o andamento da marcha e davam o ritmo ao percurso que o rancho faria. Pelas ruas, ouvia-se o coro: “(...) Ouço cantar, que alegria. Vejo o Kananga, na folia (...)".1

Era o "Kananga do Japão" que, tendo sido fundado no ano anterior, fazia o primeiro dos muitos outros desfiles que animaram o carnaval carioca e que tornou o Kananga um dos mais famosos ranchos da cidade. Mas não era a primeira vez que João Machado Guedes, então com 23 anos de idade, participava de um rancho. Muito antes, quando contava apenas dez anos, João já figurava como porta-machado do "Filhos da Jardineira" e do "Botão de Rosas", tendo ao seu lado, outros "moleques" com quem convivia na infância, tais como Antoninho, Tem-Dengo, Getúlio Marinho, Donga e Heitor dos Prazeres. João foi o único carioca dos 12 filhos do casal de baianos Félix José Guedes e "tia" Perciliana Maria Constança, daí o apelido que recebeu ainda menino e que levou por toda a vida: João da Baiana. Com esse nome, tornou-se um sambista famoso, autor de sambas conhecidos como "Batuque na cozinha", "Cabide de molambo" e "Patrão prenda seu gado", sucessos ainda hoje em qualquer roda de samba.

Neto de ex-escravos, nasceu em maio de 1887, um ano antes da abolição da escravatura. Foi criado na rua Senador Pompeu, no bairro portuário da Saúde a rua do Peu, como ele e seus companheiros de samba costumavam chamar -, e, como muitos homens negros que viviam naquela região, tornou-se estivador ainda na primeira década do século XX, aos 20 anos de idade. Porém, quando não estava literalmente pegando pesado no cais do porto, João da Baiana podia ser facilmente encontrado em alguma das muitas associações carnavalescas espalhadas pela cidade ou no terreiro de seu pai de santo João Alabá que ficava na mesma rua do seu "Kananga do Japão", na Barão de São Félix.

Morador da Zona Portuária durante boa parte de sua vida, João da Baiana frequentou a região durante toda a sua juventude. Era lá que estavam sua família, seus amigos, seu terreiro, seu trabalho e boa parte de sua diversão. Ele não se contentou só com aquele pedacinho da cidade e, como sambista e folião, conquistou muitos outros espaços: da praça Tiradentes à Lapa Boêmia; do morro da Favela ao morro de São Carlos, no Estácio; da praça Onze ao Palácio das Laranjeiras. João da Baiana conviveu entre prostitutas, capoeiras e governadores e, apesar de ter morrido pobre e relativamente esquecido, foi imortalizado posteriormente como um dos maiores sambistas de todos os tempos.

Jornal do Brasil, 24 mar. 1970. Jota Efegê.

2Porta-machado é uma espécie de guarda de honra do porta-estandarte, que abria os desfiles dos ranchos. 
Em várias entrevistas e memórias escritas sobre João da Baiana, fica clara a sua participação em vários ranchos da cidade, talvez uma vocação inspirada em seus pais, que, junto com outros migrantes trouxeram da Bahia a tradição desse tipo de festejo. De fato, a organização dos ranchos durante o carnaval parece ter sido obra principalmente dos negros baianos que, desde a segunda metade do século XIX, se instalaram nos bairros da Saúde, Gamboa e Cidade Nova. Central nesse processo foi a figura de Hilário Jovino Ferreira, Ogã do terreiro de João Alabá que fundou vários ranchos importantes no Rio de Janeiro, como "A Jardineira" e o "Rei de Ouros", este último contando com a "proteção espiritual" de Assumano Mina do Brasil, como contou Vagalume.

Hilário chegou à cidade do Rio de Janeiro em fins do século $\mathrm{XIX}^{3} \mathrm{e}$, apesar de pernambucano de nascença, teve um importante papel junto à comunidade baiana que se formou em torno da região. Era filho de ex-escravos alforriados que se mudaram de Pernambuco para Salvador, onde viveu antes de chegar no Rio de Janeiro. A exemplo de Tia Ciata e seu marido, bem como João da Baiana e outros, Hilário Jovino também buscou alianças com gente "da alta" e, como muitos outros migrantes daquela época, filiou-se à Guarda Nacional em busca de proteção e enraizamento na nova cidade. O Lalau de Ouro, como era conhecido na época, morou em vários endereços da zona portuária, como a Pedra do Sal e o beco João Inácio, no morro da Conceição. E como João da Baiana e muitos outros negros que viviam na região, também labutou no cais do porto carioca.

As ruas que circundavam a praça da República - palco da grandiosa festa do Divino Espírito Santo - , desde os tempos imperiais quando ainda se chamava Campo de Santana, eram o principal espaço festeiro da cidade. O lugar era especialmente propício a esses encontros: era aí que ficava a Estação Central do Brasil, que ligava os subúrbios ao centro da cidade. Se as áreas mais nobres da cidade eram ocupadas pelos foliões mais "civilizados", àquele lugar restavam os foliões menos favorecidos que, com seus cordões, blocos e ranchos, animavam o carnaval dos trabalhadores pobres. No mais, as agremiações sempre poderiam contar com uma ajudinha do comércio local que, formado especialmente pelos mesmos bares, quiosques, cafés etc., muito se interessava pelo grande público que concorria aos festejos. Assim, no carnaval, a região era palco das festas promovidas pelas associações carnavalescas locais, mas também de outros bairros pobres da cidade, que ali se encontravam nos dias de folguedo, fazendo de suas ruas e praças o pedaço mais animado da cidade. Ao menos para a população pobre, isso era o que fazia dali também a parte mais "suspeita" e vigiada.

\footnotetext{
${ }^{3}$ As fragmentadas referências bibliográficas apontam que ele chegou adulto no Rio de Janeiro em 1870, tendo vindo da Bahia. No entanto, alguns indícios indicam que essa data não é compatível com sua trajetória, sendo o mais provável que 1870 seja o ano de seu nascimento. Um exemplo desses indícios é a comparação com a idade de Tia Ciata, que morreu na década de 1920 antes de completar 60 anos. A bibliografia conta que entre Ciata e Jovino não havia muita diferença de idade. Assim, se ele tivesse chegado adulto em 1870, ele seria muito mais velho que Ciata. Além disso, consta que ele fundou o Rei de Ouros assim que chegou na cidade. No entanto, não há notícias desse rancho antes de 1890.
} 
No início do século XX, as freguesias de Santana, Espírito Santo e Santa Rita, onde estão localizadas a zona portuária e a Cidade Nova, concentravam, entre os anos de 1901 e 1910, 37\% das agremiações carnavalescas, entre ranchos, cordões e outras sociedades, e em maior número estavam os "terríveis cordões", vistos com negatividade pelos foliões mais "requintados", assim como pelos jornalistas e a polícia (Cunha, 2001, p.166).

Segundo Maria Clementina Pereira Cunha, em livro sobre o carnaval carioca, essa negatividade era dada principalmente aos grupos originários da parte mais pobre da cidade, ou seja, dos morros, da Cidade Nova e das imediações do porto. Para a autora,

se era aí, nesse pedaço da Capital Federal, que se concentrava a maior parte da população (e esta foi sempre pobre, negra, pouco dada a versos feitos com técnica ou a minuetos de salão), era também nela que se concentrava o Carnaval de rua tido como desagradável e primitivo, capaz de atormentar os poetas, que o chamavam de "cordões" como um meio de discriminação e denúncia. (Cunha, 2001, p.167)

O sambista Donga, também morador e frequentador da região e famoso por ter em seu nome o primeiro samba registrado com esse nome, o "Pelo telefone", fala daquela parte da cidade em seu depoimento ao Museu da Imagem e do Som:

(...) Lá era o Quartel-General devidamente assessorado pelo grande Hilário Jovino. Lá pelos lados do Depósito, da Saúde, é onde estavam os baianos. Também na rua do Costa. Mais para o centro tinha a rua da Alfândega, a rua do Hospício, atual Buenos Aires (...). Ali, era tudo negro mina, era tudo africano, tudo baiano. ${ }^{4}$

João do Rio afirmou que "o Carnaval teria desaparecido se não fosse o entusiasmo dos grupos da Gamboa, do Saco, da Saúde e da Cidade Nova" (João do Rio, 1997. p.230). Se fizermos mais um passeio pelas ruas da região na virada do século XIX para o XX, encontraremos inúmeras associações carnavalescas e dançantes vizinhas aos inúmeros candomblés, cortiços e bares que proliferavam aos montes na região. ${ }^{5}$ Algumas tinham suas sedes nesses mesmos espaços, como o "Bloco Carnavalesco Chora na Macumba" que funcionou em uma casa de cômodos da Barão de São Félix, n 152 . Algumas ainda dividiam a mesma sede, como a "União das Flores", que funcionou no início do século XX na rua General Caldwell, n 47, mesmo endereço da "Sociedade Carnavalesca Teimosos das Chamas" e da "Amadores da Estrela".

\footnotetext{
${ }^{4}$ Entrevista de Donga ao Museu da Imagem e do Som. Cf.: MUSEU DA IMAGEM E DO SOM (1970, p.78). ${ }^{5}$ Já na segunda metade do século XIX. Santana era a freguesia com o maior número de habitantes e com a maior concentração de africanos e de negros africanos e livres da cidade. Talvez por isso era lá que se concentrava também a maior parte das casas de culto de origem africana. Também era lá a maior concentração de casas coletivas. Se em 1868 a freguesia contava 154 cortiços, em 1888 já endereçava 329 cortiços. Nesse mesmo ano, o segundo lugar ficou com a freguesia do Espírito Santo, com menos da metade desse total, somando 158 cortiços. Cf. Carvalho (1995, p.140-141).
} 
Só no trecho que compreende as ruas Visconde de Itaúna, Senador Pompeu, Senador Eusébio e Barão de São Félix iremos encontrar, além das casas de santo e dos cortiços já mencionados, muitas outras "casas suspeitas". Só nesse pedacinho da região estavam os "terríveis" cordões "Rompe e Rasga”, “Teimosos Carnavalescos", "Estrela da Aurora”, "Filhos do Inferno”, “Triumpho de São Lourenço", "Nação Angola", "Filho de Satã", entre outros. Ali também se instalaram muitos ranchos, como o "Pedra do Sal", o "Rosa Branca" (que saía da casa da Tia Ciata) e o "Rei de Ouros", fundado por Hilário Jovino, só para citar alguns dos mais famosos (Cunha, 2001, p.168).

Uma característica das agremiações localizadas na região da zona portuária é a grande mobilidade apresentada por elas. É o caso dos "Amantes do Sereno" que, em 1904, tinham sede na rua Saldanha Marinho, $n^{\circ} 17$. Dois anos depois, em 1906, a mesma agremiação aparece na rua Dr. Rego Barros, no 35. Já os "Endiabrados Carnavalescos" deslocaram-se, entre os anos 1904 e 1907, ocupando três endereços diferentes: travessa são Diogo, rua Bom Jardim e Dona Feliciana. O Clube Carnavalesco "Filhos da Linda Flor" em um mesmo ano - 1904 - ocupou imóveis em duas ruas diferentes: a rua Pedro Alves e a Praia Formosa.

\section{Só nesse pedacinho da região estavam os "terríveis" cordões "Rompe e Rasga", "Teimosos Carnavalescos", "Estrela da Aurora," "Filhos do Inferno," "Triumpho de São Lourenço", "Nação Angola," "Filho de Satã"}

Há, também, casos em que um mesmo endereço é sede de mais de uma agremiação em pouco tempo. O Clube Dançante Prazer da Prainha, por exemplo, em abril de 1905 funcionava na rua Senador Pompeu, no 128. Menos de um ano depois, em fevereiro de 1906, o Prazer da Prainha estava na Visconde de Itaúna, no 44, e quem ocupava o endereço da Senador Pompeu era a Sociedade Particular Musical União dos Artistas.

Analisando também os endereços de associados é possível perceber que o local de moradia se destaca como um importante fator de aglutinação dos trabalhadores em agremiações recreativas. A Sociedade Dançante Carnavalesca Filhos da Montanha Serrada, por exemplo, apresentou em seu pedido de licença para o carnaval de 1906 o nome de 14 sócios. ${ }^{6}$ Destes, cinco moravam na rua Alcântara, dois na travessa D. Carolina Pires, dois na Visconde de Sapucahy e um na rua Bom Jardim, onde estava a sede da sociedade.

Dos 17 sócios que constam no pedido de licença para o ano de 1906 da Sociedade Carnavalesca Novo Cupido de Ouro, quatro moravam na rua Dr.

${ }^{6}$ ARQUIVO NACIONAL (doravante AN) - GIFI, pacote 178, Caixa 5359, 6C, 170 
Carmo Neto, onde se encontrava a sede da sociedade e que era também a moradia do presidente da sociedade, Cícero França Xavier. ${ }^{7}$

Também os "Teimosos Carnavalescos" apresentam essa concentração especial dos sócios. Em seu pedido de licença de fevereiro de 1906, apresenta o nome e endereço de 27 sócios. Um deles, Aarão Fernandes Medeiros, ocupava o mesmo endereço da sede do clube, na rua Barão de São Félix, no 130. Essa rua era a moradia de outros cinco sócios, três deles com a mesma numeração, indicando uma casa coletiva. Entre os sócios desse mesmo clube, dez moravam na rua dos Cajueiros. ${ }^{8}$

Ainda mais concentrados espacialmente estavam os associados do Club Carnavalesco Filhos da Prainha. Dos 20 sócios que constam do pedido de licença para o ano de 1906, 17 moravam na rua Francisco Eugênio. Pela numeração das casas, que não raro se repetia, também é possível conjecturar que alguns deles moravam em uma mesma casa, provavelmente em um cortiço. ${ }^{9}$

\section{O trabalho e o lazer}

Muitos eram os portuários que se organizavam para o lazer. Trabalhos como o de Leonardo Affonso de Pereira Miranda (2002), que analisou os clubes recreativos cariocas entre 1912 e 1922, mostram que essa afirmação vale para os trabalhadores de maneira geral, da mesma forma como mostrou Uassyr de Cerqueira (2008) em seu trabalho sobre associações de lazer em São Paulo. O que podemos perceber a partir desses e de outros estudos sobre os trabalhadores é que seria impossível distinguir a história social do trabalho da história cultural do Rio de Janeiro (Oliveira, 2005; Chalhoub, 1986).

A historiografia sobre a cidade na virada do século XIX para o XX costuma trabalhar com essa diferenciação, dividindo a história da cidade em duas vertentes: de um lado, a história social do trabalho, que tratava do trabalho propriamente dito e das associações nascidas a partir dele (sindicatos, sociedades de resistência, mutualistas etc.), dos movimentos reivindicatórios principalmente as greves e do movimento operário de uma forma mais ampla; de outro, a história cultural que lidava com as questões da "cultura popular", ou seja, das manifestações culturais como o samba, candomblés ou mesmo de revoltas dos "populares", como a Revolta da Vacina em $1904 .{ }^{10}$

Essa dicotomia acabou por produzir uma falsa ideia: a de que na cidade existem os operários, que se organizam em sindicatos, que fazem greve, enfim, que participam do movimento operário; e os "populares", tratados como coisa completamente distinta, que fazem o carnaval, a macumba, os ranchos e a revolta popular.

\footnotetext{
${ }^{7} \mathrm{AN}$ - GIFI, pacote 178, Caixa 5359, 6C, 170.

${ }^{8} \mathrm{AN}-\mathrm{GIFI}, 6 \mathrm{C}, 171$.

${ }^{9} \mathrm{AN}$ - GIFI, pacote 178, Caixa 5359, 6C, 170.

${ }^{10}$ Para uma visão ampla sobre este assunto, ver: Batalha e Silva (2004).
} 
Mas será que é possível fazer essa diferenciação e dividir os moradores pobres da cidade em grupos tão distintos? Não fariam eles parte dos mesmos grupos e não estariam eles participando das mesmas lutas, assim como das mesmas diversões?

Falar das relações construídas no trabalho e na organização sindical é pouco para entender o universo dos trabalhadores, já que esse universo era muito maior e mais complexo, envolvendo redes de relações que vão além daquelas construídas no processo produtivo. Segundo E. P. Thompson,

a classe se delineia segundo o modo como os homens e mulheres vivem suas relações de produção e segundo a experiência de suas situações determinadas, no interior do "conjunto de suas relações sociais", com a cultura e as expectativas a eles transmitidas e com base no modo pelo qual se valeram dessas experiências em nível cultural (Thompson, 2001, p.277).

Perceber a cultura como parte integrante da formação dos trabalhadores passou a fazer parte dos métodos e interesses dos historiadores da classe operária no Brasil, que passaram a ir além das experiências relativas à ação política direta, trazendo à tona outras situações vividas no cotidiano e fora do local de trabalho (Decca, 1987). Portanto, é importante atentarmos para o fato de que a classe trabalhadora não pode ser considerada um elemento isolado do restante da sociedade, nem é formada por pessoas que só existem no seu local de trabalho. A classe trabalhadora é formada por homens e mulheres que, além de trabalharem, vivem outras experiências: lutam, se encontram, moram, comem, bebem, sofrem... e se divertem!

\section{Folias suspeitas}

Por ficarem próximas ao cais, as ruas da Zona Portuária foram o endereço de muitos outros trabalhadores do porto carioca. Situada nos bairros considerados "suspeitos" pela polícia republicana, que tinha como foco o controle social, a região foi alvo da repressão dessa mesma polícia, que prendia aqueles que considerava "vadios" e "promotores da desordem". Na capital da recémfundada república, as multidões anônimas que ocupavam a via pública foram vistas como sinônimo de barbárie e atraso. Assim, o modelo de civilização adotado de cima para baixo representou também, por meio do aparato repressivo legitimado por teorias científicas, a imposição da vigilância, do controle e da disciplina para toda a população. Nesse conjunto, os negros pareceram merecer atenção redobrada.

A suspeição aos bairros contíguos ao porto certamente tinha base no fato de ser aí uma região de habitações populares - muitas vezes coletivas - e especialmente por abrigar grande número de negros. Dessa forma, a associação pela polícia de muitas dessas organizações com os "vagabundos" e "desordeiros" era inevitável e justificava, pelo menos aos seus olhos, a atuação repressiva. 
Ao olhar desconfiado da polícia somavam-se o das elites e de parte da imprensa, que muitas vezes deixava pública a sua visão preconceituosa em relação à região, sempre associada aos negros e às manifestações culturais associadas aos negros. Era comum as pessoas se depararem, na imprensa, com críticas de jornalistas fiéis ao ideal da civilização, praguejando contra a selvageria dos negros e seus batuques. Notícias sobre a concorrida Festa da Penha dão conta do quão medonho parecia, aos olhos das elites, a diversão daqueles homens:

Os verdadeiros romeiros, devotos da Penha se dirigiam para a festa tradicional a ouvir as músicas, fazer deprecações, cumprir promessas. Este elemento ordeiro e festivo, cerca de 1 hora da tarde, começou a abandonar o arraial. Entretanto, começava a chegar o pessoal duvidoso; e ao mesmo tempo que em um canto se formavam os cordões terríveis, ameaçadores, selvagens, em outro canto reuniam-se os sambas, não menos terríveis, muito mais selvagens. A esse tempo, o comércio de aguardente e do vinho barato chegava ao máximo desenvolvimento (...) Não tardou muito a (acontecer um conflito). Na ala esquerda das barracas, súbito ouviu-se a detonação de uma arma de fogo. O povo e uma turba de policiais precipitaram-se para o local do conflito. (...) Era a barraca no 1, em cuja entrada se lia em grossas letras de vermelhão: FLOR DA SAÚDE. Era pois, certo que a FLOR DA SAÚDE não podia desmentir sua negra tradição. ${ }^{11}$

Sambas, cordões e o bairro da Saúde são identificados, pelo Jornal do Commercio de 1907, com a selvageria na Festa da Penha. Essa festa, que vinha desde os tempos coloniais, se realizava durante todos os fins de semana do mês de outubro, teve seu apogeu em fins do XIX e início do XX e era considerada uma espécie de avant-première do carnaval carioca. ${ }^{12}$ Lá os sambistas lançavam os sambas que seriam, ou não, sucesso no carnaval. Heitor dos Prazeres dizia que a aceitação das composições nesse evento tranquilizava os autores, confessando que ele mesmo ficou conhecido a partir da Festa da Penha. João da Baiana era frequentador assíduo das festas, assim como os sambistas Donga, Heitor dos Prazeres, Sinhô, Caninha, Pixinguinha e as tias baianas que tinham barracas na festa, incluindo Tia Ciata. Era como se, nos fins de semana de outubro, a Pequena África se deslocasse inteira para a Penha, assim como boa parte da cidade. Rachel Soihet coloca que, entre os brasileiros, um contingente significativo dos frequentadores era de negros e ressalta a importância que teve a comunidade de negros baianos que armavam suas barracas, ponto de encontro e de identidade cultural. A mesma autora afirma que era em torno dessas barracas que se formavam as rodas de samba. Eram barracas de nomes sugestivos como "Reino da África", "Sultana da Bahia", "Flor da Cidade Nova” e a já citada "Flor da Saúde”, entre outras (Soihet, 1998).

"Jornal do Commercio, 22 out. 1907.

12Sobre a Festa da Penha, ver: Soinet (1998). 
Como João da Baiana, outros trabalhadores do porto ficaram famosos por sua participação na Festa da Penha, nas rodas de samba e, principalmente, na organização de associações carnavalescas. Elói Antero Dias, por exemplo, mais conhecido por Mano Elói, fazia parte do quadro de sócios da "Sociedade de Resistência dos Trabalhadores em Trapiche e Café" desde pelo menos $1910^{13}$ e sua atuação como organizador de ranchos e blocos carnavalescos andava junto com sua atuação na política portuária. Nascido no ano de 1889, em Resende, interior do estado do Rio de Janeiro, Mano Elói chegou à cidade carioca em 1903 e morou e frequentou a zona portuária durante muito tempo, antes de fixar residência no morro da Serrinha, no bairro suburbano de Madureira, onde foram morar muitos outros portuários expulsos pelas reformas urbanas na segunda década do século XX. Nos seus tempos de menino, costumava vender balas no Campo de Santana e, mais tarde, já atuando no cais, costumava percorrer os redutos de sambistas da cidade, na Pedra do Sal, no morro da Favela e Santo Antônio, além de ser frequentador de terreiros de macumba (Valença, 1981).

Mas, ao contrário de seu colega de profissão, sua atuação como sambista e organizador de blocos e ranchos parece ter sido mais forte nos subúrbios cariocas. Na década de 1920, participou ativamente da fundação das escolas de samba "Deixa Malhar" e "Portela", além do "Bloco Carnavalesco Prazer da Serrinha". Tempos depois, já na década de 1940, Mano Elói fundou, junto a outros sambistas que trabalharam no cais do porto, como Sebastião Molequinho, João "Gradim" e Aniceto do Império — sobrinho de Hilário Jovino —, uma das mais antigas escolas de samba do Rio: a "Império Serrano", herdeira do antigo "Prazer da Serrinha". Até os dias de hoje, os membros do "Resistência" — atualmente chamado de "Sindicato dos Arrumadores do Rio de Janeiro" — têm entrada livre na quadra da Império Serrano, bastando apresentar a carteira de sindicalizado. ${ }^{14}$

Entretanto, para além dos estivadores que ficaram mais ou menos famosos no mundo do samba e do carnaval, como João da Baiana, Hilário Jovino, Mano Elói, Sebastião Molequinho, Aniceto da Serrinha, João Gradim etc., certamente muitos outros homens do cais tomaram parte dos inúmeros grupos festeiros da cidade. Associações carnavalescas em geral e clubes dançantes eram, junto aos botequins, a principal forma de lazer da população pobre em geral.É importante percebermos essa ligação mais íntima que muitos dos portuários mantinham com alguns desses centros recreativos, pois tanto quanto as de cunho sindical, como a já citada "Sociedade de Resistência dos Trabalhadores em Trapiche e Café", mas também a "União Operária dos Estivadores" e outras, marcaram a experiência dos portuários, fazendo parte do universo cultural daqueles trabalhadores.

\footnotetext{
${ }_{13}$ Livro de Matrículas da Sociedade de Resistência dos Trabalhadores em Trapiche e Café, encontrado no Arquivo do atual Sindicato dos Arrumadores do Rio de Janeiro. O nome de Elói Antero Dias consta como filiado em 1910, mas sua filiação pode ser anterior, pois nesse livro estão os nomes de alguns sócios fundadores como admitidos no sindicato nesse mesmo ano.

${ }^{14}$ Conversas com os membros do Sindicato dos Arrumadores do Rio de Janeiro.
} 
Bucy Moreira, neto de Tia Ciata, lembrou-se dos homens que frequentavam as festas de sua avó, incluindo seus familiares: "eles eram de festa, mas também de trabalho (...). A maioria trabalhava na estiva. Tive mais de vinte primos na estiva, conferentes, estivadores. Tive um primo presidente da estiva (...)" (Moura, 1995, p.71).

Para que as sociedades recreativas pudessem sair às ruas nos dias de folguedo ou promover bailes dançantes nos outros dias do ano, era preciso antes tirar uma licença, que deveria ser renovada anualmente. Esses pedidos eram encaminhados às autoridades policiais, que investigavam a sociedade em questão e decidiam se concediam a licença ou não. Para que pudessem continuar com seus divertimentos, era preciso "provar" que eram pessoas ordeiras, interessadas apenas em divertir-se sem maiores consequências.

Em 08 de fevereiro de 1906, por exemplo, o "Grêmio Carnavalesco Flor dos Navegantes", com sede na rua Senador Pompeu, nº 62, pediu licença para sair às ruas nos dias de carnaval. Dias depois, o inspetor Manoel Matheus Nunes, da Inspetoria da $2^{\mathrm{a}}$ seção da $3^{\mathrm{a}}$ Circunscrição Urbana, escreve em ofício que "o grupo é composto de rapazes empregados na nossa Marinha Mercante e alguns estivadores e que nenhum destes eu conheço como desordeiro". ${ }^{15}$

Acompanhado desse pedido de licença, estava o pedido do ano anterior, quando a sede do grêmio era no Largo do Depósito, no 54 . Anexos a esse primeiro pedido estavam os estatutos da agremiação, que dizia em seu primeiro artigo que o grupo tem por fim "cooperar no terreno moral para o desenvolvimento dos folguedos dedicados ao Deus Momo" e, logo em seguida, que "serão respeitados os direitos dos sócios, sem exclusivismo ou preconceitos que possam afetar o principal [objetivo] do grupo: Prazer e União".

Talvez para mostrar a seriedade da associação requisitante, os estatutos das associações recreativas, muitas vezes, eram anexados ao pedido anual de licença para funcionamento. Normalmente, esses estatutos seguiam um mesmo padrão de organização, listando sempre os objetivos do grupo, a forma como se dava a admissão dos sócios, quais seus direitos e seus deveres.

O “Clube dos Aborrecidos", por exemplo, com sede na rua Visconde de Itaúna, $n^{\circ} 229$, anexou seus estatutos para renovar sua licença e sair no carnaval do ano de 1906, além de promover bailes durante o mesmo ano. No artigo $1^{\circ}$ do Capítulo 1 dos estatutos diz-se que "o Clube dos Aborrecidos, fundado a 26/03/1905, é composto de ilimitado número de sócios e tem por fim proporcionar a todos além dos festejos carnavalescos, bailes e quaisquer outros divertimentos".16

Assim, o artigo $1^{\circ}$ dos estatutos da União Operária dos Estivadores, de 1904, dizia que "esta associação fundada aos treze de setembro de 1903, na cidade do Rio de Janeiro, Capital Federal dos Estados Unidos da República do Brazil, onde é a sua sede, será composta de ilimitado número de sócios, de qualquer nacionalidade".17

\footnotetext{
$\overline{{ }^{15} \mathrm{AN}-\mathrm{GIFI}-6 \mathrm{C}-171}$

${ }^{16} \mathrm{AN}-\mathrm{GIFI}-6 \mathrm{C}-170$

${ }^{17}$ AN - 10 Ofício de Títulos e Documentos. Sociedade Civil. Livro A-1. Registro da União dos Operários Estivadores, O5 de agosto de 1904.
} 
Essa referência à nacionalidade dos sócios também é comum nos estatutos das sociedades carnavalescas. Os estatutos da Sociedade Carnavalesca Heróis da Mocidade, com sede na rua Marquês de Pombal, nº 30, dizem em seu artigo $1^{\circ}$ que "o número de sócios é ilimitado, permitindo indivíduos de qualquer nacionalidade".18

Em alguns estatutos, como do Clube Carnavalesco Caprichoso de Jacarepaguá, aprovados em 23 de março de 1902, a democratização dos sócios aparece ainda mais explícita. Assim, o artigo $2^{\circ}$ do Capítulo 1 dos mesmos estatutos, diz que "poderão serem (sic) admitidos como sócios todo e qualquer indivíduo, sem distinção de cor e nacionalidade". Aqui também é possível fazer um paralelo com os estatutos de associações operárias, mais especificamente a Sociedade de Resistência de Trabalhadores em Trapiche e Café, que nos estatutos renovados de 1906 afirma que a mesma tinha por fim "procurar a união de todos os trabalhadores, sem distinção de nacionalidade, cor e religião". ${ }^{19}$

\section{"Serão respeitados os direitos dos sócios, sem \\ exclusivismo ou preconceitos que possam afetar o principal [objetivo] do grupo: Prazer e União"}

A preocupação em informar a "boa procedência" dos sócios aparece em vários estatutos de associações carnavalescas. Essa era, talvez, uma forma de facilitar a conquista do pedido de licença, uma vez que esses divertimentos populares muitas vezes eram associados à desordem e às "classes perigosas".

Assim, a "Caprichosos de Jacarepaguá" não distinguia os sócios por cor ou nacionalidade, mas deixava claro em seus estatutos que só seriam aceitos sócios que dessem "boas referências de sua conduta, sendo essa apresentada, em proposta, por dois sócios quites". A já mencionada "Sociedade Carnavalesca Heróis da Mocidade" também explicita que só seriam aceitos sócios que atestassem "ocupação honesta".

Querendo mostrar sua idoneidade e, assim, conseguir a licença para os bailes e para sair nos três dias de carnaval, o artigo $2^{\circ}$ do segundo capítulo do estatuto do já mencionado "Clube dos Aborrecidos" dizia que para ser admitido o sócio teria que ser "proposto por um sócio quites (...) e que garanta a idoneidade do proposto", além de "reconhecer a moralidade e ocupação honesta do sócio proposto, bem assim não se achar o mesmo envolvido em processo algum". ${ }^{20}$

O Capítulo 2 dos estatutos do Congresso dos Pirilampos, grupo recreativo com sede na rua Senhor dos Passos, $n^{\circ} 4$, afirma em seu artigo $3^{\circ}$ que para ser sócio do dito congresso é preciso "ser de bom comportamento e não achar-se

${ }^{18} \mathrm{AN}-\mathrm{GIFI}-6 \mathrm{C}-170$

${ }^{19} \mathrm{AN}-\mathrm{GIFI}-6 \mathrm{C}-170$

${ }^{20} \mathrm{AN}-\mathrm{GIFI}-6 \mathrm{C}-170$. 
envolvido em processos crime", além de também ser necessário ser proposto por outro sócio. O mesmo acontecia com os estatutos do "Grêmio Carnavalesco Estrela dos Dois Diamantes", que funcionava na rua do Retiro de Santo Amaro $\mathrm{n}^{\circ}$ 13, e fundado em 8 de novembro de 1895. Podendo ser admitido "número ilimitado de sócios, de qualquer nacionalidade", só poderiam ser admitidos, segundo os estatutos, maiores de 16 anos de "reconhecida moralidade" e desde que "proposto por um sócio que atestar suas qualidades".

De acordo com os estatutos de 1910 da União dos Operários Estivadores, só "seriam admitidos os trabalhadores da estiva com bom comportamento" e não seriam admitidos sócios que tivessem "sido condenados por crimes contra a propriedade ou por embriaguez habitual".22

Dessas semelhanças em torno de um padrão que sequer pode ser definido como nacional, ${ }^{23}$ podemos deduzir que as sociedades recreativas e/ou carnavalescas eram, inclusive na sua forma de organização e estruturação formal, sociedades de trabalhadores tanto quanto as sociedades com caráter de resistência ou sindical, ainda que construídas a partir de outras características e necessidades da classe.

Roberto Moura reforça a relação entre os trabalhadores portuários e a organização do carnaval. Segundo ele, como sindicato negro, a "Sociedade de Resistência dos Trabalhadores em Trapiche e Café” teve o seu próprio rancho: o "Recreio das Flores", na Saúde, que teria Marinho da Costa Jumbeba, neto de Tia Ciata, como mestre-sala. Sua irmã Lili Jumbeba relembrou os tempos em que o rancho brilhava em seus desfiles: "O Recreio trazia aqueles holofotes do cais, que ele era estivador e tinha licença de trazer. O Recreio das Flores era do cais do porto, podia outro vir bom, mas o Recreio tinha que ganhar (...)" (Moura, 1995, p.72).

O "Recreio das Flores" funcionou em diferentes endereços da zona portuária que já conhecemos bem. Até pelo menos 1908 teve sede na rua Barão de São Félix, nº 211; em 1912, na rua da Saúde, nº 231, e em 1913 funcionava na rua do Livramento, n 83. Em 1912, Miguel Rosso, sócio fundador da "União Operária dos Estivadores”, era o vice-presidente desse rancho, que contava com a presença de outros estivadores entre os membros de sua diretoria. ${ }^{24}$ Certamente, esse rancho fez a alegria de muitos portuários nos dias de carnaval, mas também nos bailes que promovia durante o ano.

Mas nem sempre tudo eram flores para o "Recreio das Flores" e em alguns momentos, a polícia se intrometeu nos planos dos foliões. Assim, se no ano de 1913 o comissário de polícia João Inácio do Espírito Santo informou ao chefe de Polícia que a dita sociedade era composta "de operários, estivadores e empregados do comércio, rapazes ordeiros contra os quais nada consta nesta delegacia,"25 em alguns momentos não era essa a opinião das autoridades.

\footnotetext{
$\overline{{ }^{21} \mathrm{AN}-\mathrm{GIFI}-6 \mathrm{C}-170}$

${ }^{22}$ AN - Estatuto da União dos Operários Estivadores, 1910. 10 ofício de registro de títulos e documentos, Estatutos de sociedades civis, código 66, seção de guarda SDJ, vol. 27, documento no 498. Art. 60.

${ }^{23}$ Lembremos aqui que a ideia do "número ilimitado de membros" já estava presente nas definições estatutárias da Sociedade Londrina de Correspondência, tomada por Thompson como marco inicial das associações de classe dos trabalhadores ingleses. Cf.: Thompson (1987)

${ }^{24} \mathrm{AN}$ - GIFI - 6C - 367 (pacote 418, Caixa 5556).

${ }^{25} \mathrm{AN}$ - GIFI - 6C - 432 (pacote 459, Caixa 5621).
} 
No ano de 1915, por exemplo, o "Recreio das Flores" não teve permissão para continuar suas atividades de lazer, frustrando as expectativas de seus seguidores. 0 comissário Salvio de Azevedo, da $4^{\mathrm{a}} \mathrm{DP}$, assim escreveu ao chefe de Polícia:

(...) informo que nada me consta que desabone a Diretoria do Clube Recreio das Flores (...), no entanto os sócios e frequentadores do aludido clube são ladrões, vigaristas e indivíduos que vivem exclusivamente de jogos de azar e por diversas vezes presos e alguns processados por esta delegacia. O fim do clube é explorar jogos de azar de toda espécie e reunir em sua sede os indivíduos citados acobertados por uma Diretoria composta de membros que graciosamente $\mathrm{xxx}$ (sic) as suas assinaturas como Diretores sem a menor responsabilidade ou intervenção direta. ${ }^{26}$

Aos olhos das autoridades policiais, apesar de nada de concreto desabonar sua diretoria, o "Recreio das Flores" tornava-se um perigo na medida em que seus sócios eram reconhecidos por "ladrões e vigaristas" que, segundo o comissário, eram acobertados pela diretoria. Na opinião da polícia, a finalidade do clube, longe de ser a de diversão de trabalhadores pobres, era promover os jogos de azar. Talvez o fato de alguns deles já terem sido processados pela polícia dava margem para que fossem considerados "ladrões e vigaristas".

Em artigo sobre Clubes Recreativos no Rio de Janeiro da segunda década do século XX, Leonardo Pereira apontou constantes diferenças na forma como participantes e autoridades viam esses clubes, mas essa visão negativa não era uma peculiaridade de comissários e delegados. Para o autor, cronistas de jornais cariocas também ajudaram a construir uma visão negativa dos clubes dançantes, sempre os caracterizando-os como "antros de perdição e violência". Para muitos esses clubes eram o lugar da "fina flor da zona escura", onde o "negro de azeviche" dançava com a dama "da mesma cor", como se referiu o Correio da Manhã ao "Recreio das Turmalinas", em 1918. ${ }^{27}$ Essa imagem pejorativa que o jornalista construiu do clube indica o abismo que separava as concepções dos letrados sobre aqueles bailes e o modo como eram vividos pelos que ali encontravam sua diversão (Miranda, 2002). Frequentados especialmente por trabalhadores pobres, gente que atuava no serviço informal, grande parte deles pretos e pardos, as reuniões nesses clubes festeiros representavam, pela sua composição tanto racial quanto de classe, um perigo para aqueles que não iam a seus salões.

Como aconteceu com o "Recreio das Flores", nem sempre as coisas aconteciam como o planejado e muitos clubes tiveram seus pedidos de licença indeferidos, ou suspensos. A “Sociedade Dramática Particular Furtado Coelho", por exemplo, apresentou seu "pedido de licença para realização de diversões recreativas" ao chefe de Polícia Cardoso de Castro em 1904. Apesar de o pedido ter sido acompanhado por uma autorização da tesouraria do "Apostolado do

\footnotetext{
$\overline{{ }^{26} \mathrm{AN}-\mathrm{GIFI}-\mathrm{IJ} 6563 .}$

${ }^{27}$ Correio da Manhã, $1^{\circ}$ jun. 1918.
} 
Coração de Jesus da Matriz de Santa Rita", informando que 15\% dos rendimentos da associação seriam destinados a essa instituição, ele foi indeferido sob a alegação de que a sociedade encobriria jogos proibidos. ${ }^{28}$

O "Clube Couraceiros do Inferno" também teve seu pedido de licença negado pelas autoridades em 1914 . Com sede na rua de Santana, no 55, na praça Onze, o clube foi considerado pelo inspetor do corpo de segurança um local "frequentado por homens e mulheres de baixa esfera, que ali provocam constantes conflitos, tendo, há pouco tempo, havido um assassinato em sua sede". O comissário de segurança pediu seu fechamento "como medida de ordem social", já que, na sua visão, os que participavam das festas do "Couraceiros" eram a "escória social". ${ }^{29}$

Havia também alguns casos em que o pedido de licença era concedido, mas não sem antes receber, por escrito, uma série de recomendações. Foi o caso, por exemplo, do "Grêmio Carnavalesco Dália de Ouro", que tinha sede na rua General Caldwell, no 143 . A permissão para sair no carnaval foi concedida, mas o próprio chefe de Polícia Antônio Augusto Cardoso de Castro impõe restrições:

não haver jogos proibidos e os ensaios não excederem às (sic) 10 horas da noite e os bailes das 2 da madrugada, sendo que os ensaios carnavalescos apenas poderão ter lugar aos domingos e dias feriados (sic) de 20 de janeiro até o carnaval e diariamente 8 dias antes, e não lhe sendo permitido sair às ruas nem realizar diversões com entradas retribuídas sem licença especial da polícia. O grêmio funcionará de portas abertas e dará franco acesso aos delegados auxiliares e autoridades policiais da circunscrição. Às demais autoridades policiais será também franco o ingresso, no caso de perturbação da ordem em quaisquer dependências do recinto social. ${ }^{30}$

Recomendações parecidas foram dadas em 1906 ao Clube Carnavalesco Filhos das Lusitanas, com sede na rua da América, n 28; à Sociedade Dançante Carnavalesca Triunfo Flor da China, entre outros.

Em 1915, Cypriano José de Oliveira, presidente da "Sociedade Familiar Dançante e Carnavalesca Clube dos Mangueiras", com sede na vila de Marechal Hermes, encaminhou um pedido de licença para que sua sociedade pudesse funcionar. O chefe de Polícia pede informações ao inspetor da $2^{\mathrm{a}}$ Delegacia Auxiliar sobre a diretoria do Clube. Este responde com as seguintes palavras:

A Sociedade Dançante e Carnavalesca Clube das Mangueiras tem a sua sede em um botequim à Av. $1^{\circ}$ de Maio no 6 , na Vila de Marechal Hermes. Cypriano José de Oliveira é o presidente desta sociedade; figura nesta seção registrado em prontuário, como grevista, e como tal já foi processado. Caralampio Trille é sócio deste Clube, esse mesmo indivíduo é agitador, revolucionário perigoso, e em 1904 esteve envolvido e tomou parte saliente

${ }^{28} \mathrm{AN}-\mathrm{GIFI}, 6 \mathrm{C}, 135$.

${ }^{29} \mathrm{AN}$ - GIFI. Pacote 489, Caixa 5668.

${ }^{30} \mathrm{AN}-\mathrm{GIFI}, 6 \mathrm{C}, 170$. 
nas greves e acontecimentos ocorridos neste ano. (...) os demais sócios são operários e empregados da estiva. ${ }^{31}$

É interessante perceber, como apontou Cunha, o esforço policial em associar formas diversas de "perigo": a um grupo de foliões onde figuram grevistas, revolucionários e talvez metidos com a revolta da vacina. Junta-se a isso o fato de a sede funcionar em um botequim. Era mais que suficiente para que a suspeição que recaía sobre esse tipo de agremiação tomasse forma (Cunha, 2001, p.201). O sócio "agitador e revolucionário" de nome suspeito era um espanhol anarquista com um longo histórico de militância em seu país e que, no Brasil, participou de várias sociedades operárias, ajudando a fundar jornais libertários como A Greve, em 1903. No início dos anos 1910, Caralampio Trille presidia a Sociedade Operária Fraternidade e Progresso da Gávea. ${ }^{32}$ Já o "grevista" Cypriano José de Oliveira era carregador no cais do porto. Ele foi fiscal geral e, anos depois, em 1923, ele chega a ser presidente da "Sociedade de Resistência dos Trabalhadores em Trapiche e Café”, onde exerceu forte militância no cais. Com uma diretoria potencialmente "perigosa", o pedido de licença foi negado ao "Clube dos Mangueiras".

Em março de 1912, a "Sociedade Carnavalesca Triunfo dos Beija-Flores" encaminhou o pedido de licença anual para que pudesse funcionar. A sociedade tinha sede na rua Bom Jesus do Monte, $n^{\circ} 7$, no morro da Favela, e tinha como membros de sua diretoria homens de diferentes profissões. O presidente Antônio Campos dos Santos não declarara profissão, mas o vice, Severino Eduardo Pimentel, era pedreiro; o $1^{\circ}$ secretário, Joaquim de Andrade Bastos, era portuário e trabalhava nas descargas da estação marítima; o $2^{\circ}$ secretário, Francisco de Mello e Albuquerque, era operário do arsenal de marinha; o fiscal Júlio de Andrade Bastos trabalhava como adido na Estrada de Ferro Central e o $2^{\circ}$ fiscal, Joaquim Bernardo, disse trabalhar em um armazém. ${ }^{33}$ Apesar de as informações não serem claras, encontramos um Joaquim Bernardo entre os sócios fundadores da União Operária dos Estivadores, podendo se tratar da mesma pessoa. Provavelmente Joaquim trabalhava em um dos muitos armazéns que guardavam mercadorias a serem embarcadas pelos estivadores no cais do porto.

No dia 20 de março, o inspetor do corpo de segurança informou ao chefe de Polícia que aquela sociedade era composta de "desordeiros e vagabundos, não se encontrando pessoa alguma que abonasse a conduta dos mesmos". Na semana seguinte, em um parecer divergente do inspetor, o comissário esclarecia que a mesma sociedade era composta de "homens do trabalho com domicílio certo, não havendo inconveniente algum na aprovação dos estatutos”. Alguns dias depois o inspetor se pronuncia novamente com resultados de uma sindicância em que apurou que alguns membros da dita sociedade já haviam tido problemas com a polícia. Diante da divergência de opiniões entre as autoridades, ficou decidido que a licença seria concedida caso fossem eliminados de seus quadros os "elementos nocivos". Ao contrário do que muitas vezes ocorria em situações semelhantes, a licença foi concedida dias depois. No entanto, o $2^{\underline{0}}$ delegado informou que o presidente se comprometera a eliminar os sócios

${ }^{31} \mathrm{AN}-\mathrm{GIFI}, \mathrm{IJ} 6135$

32Sobre Caralampio Trille: A Epoca, 19 set. 1913 e 3 out. 1913.

${ }^{33} \mathrm{AN}$ - GIFI, Pacote 416, Caixa 5553. 
"nocivos". Esse comprometimento do presidente da tal sociedade parece ter sido o diferencial para que a licença fosse liberada.

No entanto, não sabemos se os tais sócios considerados nocivos, ou seja, os "desordeiros e vagabundos" apontados pelo inspetor foram mesmo eliminados dos quadros da sociedade ou se aquela foi apenas uma estratégia para que a sociedade pudesse conseguir a licença. Afinal, existe aqui um diferencial entre o olhar da polícia e o olhar dos próprios membros da sociedade. Provavelmente, nem o presidente e nem os outros membros se viam dessa forma e não tinham de si a imagem que o inspetor de segurança tentou projetar, nem mesmo o comissário parecia compartilhar da opinião do inspetor, em uma prova do quão subjetivo poderia ser o julgamento. Talvez só o fato de funcionar no morro da Favela e parte da sua diretoria ser composta por homens de profissões simples e eventuais, como pedreiros, carregadores e trabalhadores em armazéns, fosse o motivo de o inspetor considerar a sociedade perigosa e seus membros "desordeiros e vagabundos". De qualquer forma, mais do que expressar que concordavam com a visão da autoridade, ao prometer a eliminação dos sócios "nocivos", os membros da sociedade estariam buscando uma maneira de continuar seus divertimentos e evitar problemas com a polícia. Casos como esses podem nos aproximar das experiências dos trabalhadores do porto nos momentos de lazer, além de indicar como as autoridades atuavam na vida dessas pessoas a imensa diferença entre a percepção que esses trabalhadores tinham de suas próprias práticas e a visão da polícia.

\section{Ao prometer a eliminação dos sócios "nocivos," os membros da sociedade estariam buscando uma maneira de continuar seus divertimentos e evitar problemas com a polícia}

No entanto, a relação da polícia com aqueles divertimentos nem sempre era tão dura e dicotômica. No dia 23 de março de 1904, por exemplo, o Correio da Manhã divulgou uma crítica a um policial que teria se entregado aos prazeres das danças em um daqueles salões:

Há dias realizou-se um baile numa sociedade existente na rua Espírito Santo, onde a polícia já tem penetrado por várias vezes para apaziguar conflitos que sempre ali se dão. A essa festa presidiu como autoridade policial um tal suplente Mattos, indivíduo já célebre por suas façanhas. Mattos, esquecendo-se, talvez, da compostura que devia conservar, não resistiu às tentações de um "choroso maxixe" e a ele se entregou de corpo e alma, num delírio infernal. Rodeado por mulheres, foi praticando ele cenas que muito depõem contra a autoridade incumbida de manter a ordem, tornando-se assim o primeiro a dar o mau exemplo. Que magnífico mantedor da ordem! ${ }^{34}$

${ }^{34}$ Correio da Manhã, 20 mar. 1904. Coluna: "Na Polícia e nas Ruas", p.2. 
Os policiais também eram trabalhadores pobres e muitas vezes vizinhos daqueles clubes e de seus frequentadores. Talvez o tal suplente Matos já frequentasse aquela associação ou qualquer outra quando não estava de serviço, mas, para o jornalista, a atitude do policial depunha completamente contra a sua função de autoridade responsável pela manutenção da ordem dentro do salão onde, segundo ele, ocorriam constantes conflitos.

No mais, se por um lado são inegáveis o preconceito e a suspeição em relação aos divertimentos dos pobres, é certo também que eles souberam criar estratégias para driblar a repressão policial e o olhar atravessado dos letrados.

Uma das formas encontradas pelos trabalhadores para desvincularem-se da fama de desordeiros e conseguirem das autoridades a permissão para se divertirem livremente em suas agremiações foi a de nomear essas mesmas agremiações com nomes que remetiam aos padrões de comportamento desejados pela elite civilizada. Na região portuária é possível encontrar associações com nomes que remetem à ingenuidade e que em nada lembravam a violência ou a desordem, características tão comumente associadas aos moradores daquela região: "Amantes do Sereno", "Amadores da Estrela", "Filhos da Linda Flor", "Flor da Inocência”, "Pombinhos de Ouro", "Prazer dos Anjos" etc.

Entretanto nem todos os grupos estavam preocupados em dar à sua sociedade uma imagem oposta àquela que as elites faziam da região e de seus moradores. É bastante comum encontrar agremiações com nomes que certamente faziam as autoridades policiais "torcer o nariz", como "Endiabrados Carnavalescos", "Teimosos das Chamas" ou "Rei das Chamas", "Sociedade Carnavalesca Chuveiro do Inferno", "Bloco Carnavalesco Fruta Proibida”, entre outras.

Havia também alguns clubes onde o nome deixava claro o tipo de vínculo entre os seus associados. Esse vínculo poderia ser a região onde se encontrava, como os "Paladinos da Cidade Nova" e os "Filhos da Prainha"; ou à categoria profissional, como é o caso dos "Marítimos Carnavalescos" ou do "Bloco dos Açougueiros", entre outros.

\section{Os ranchos e o carnaval civilizado}

Uma outra estratégia dos trabalhadores para alcançar o direito de brincar o carnaval sem maiores interferências da polícia foi a tentativa de se adequar a certos padrões definidos pelas elites como "adequados". Para Maria Clementina Pereira Cunha, os ranchos carnavalescos foram centrais nesse processo. Formados no início do século XX no seio da comunidade baiana, os ranchos se distinguiram das formas mais espontâneas de folia carnavalesca como os cordões justamente por sua organização (Cunha, 2001, p.218).

Em uma de suas entrevistas a Vagalume, Hilário demonstrou seu orgulho em ver desfilar o "Rei de Ouro":

Naquele tempo o Carnaval era feito pelos cordões de velhos, pelos zé-pereiras e pelos cucumbis da rua João Caetano e da rua do Hospício. O Rei de Ouro, meu Vagalume, quando se apresentou 
com perfeita organização de rancho no Rio de Janeiro: porta-machado, porta-bandeira, batedores, etc. Perfeitamente organizado, saímos licenciados pela polícia. Quem se interessou pela nossa licença foi o velho Araújo, o escrivão da antiga Quinta Pretoria (...). Naquela Pretoria trabalhavam e eram nossos amigos os senhores Serafim, Augusto e Frederico Moss de Carvalho, Mauro de Almeida, hoje cronista carnavalesco (...). Era também empregado na Pretoria Avelino Pedro de Alcântara, que foi eleito nosso primeiro vice-presidente. Devo dizer que o Rei de Ouro foi um sucesso. ${ }^{35}$

Ainda segundo Cunha, a conexão que pessoas como Hilário Jovino e a famosa baiana Tia Ciata estabeleceram com elementos influentes da sociedade foram de grande importância no sentido de buscar a proteção de certas práticas culturais estigmatizadas e mesmo perseguidas.

Os ranchos nasceram com aparência de "espaço da ordem" e contaram com o apoio de intelectuais e com a garantia do próprio aparato policial, tanto que o "Rei de Ouro", que tinha proteção espiritual do famoso africano Pai Assumano Mina do Brasil, contou com um empregado da polícia na vice-presidência de sua primeira diretoria. Cunha afirma que os ranchos consolidaram um novo padrão de brincar o carnaval, aproveitando-se da "experiência compartilhada das habitações coletivas, da ajuda mútua, dos terreiros de candomblé e do trabalho no porto" (Cunha, 2001, p.218).

Muitos trabalhadores do cais frequentaram esses espaços de convívio e lazer como por exemplo, Mano Elói e outros membros de sindicatos portuários, que exerceram cargos de chefia em clubes carnavalescos e dançantes concomitantemente às suas atuações no sindicato. Entre os sócios da "Sociedade de Resistência dos Trabalhadores em Trapiche e Café" encontramos outros nomes: ${ }^{36}$ Antenor dos Santos, por exemplo, era companheiro de Mano Elói nesse sindicato, mas também nos jongos organizados por eles no morro da Serrinha. ${ }^{37}$ Antenor chegou a ser presidente da Portela e provavelmente é ele o Antenor que, em 1905, foi mestre-canto do "Grêmio Infantil Rosa do Engenho Velho".38 Os exemplos se seguem entre os membros desse sindicato: João Campos era, em 1912, secretário da "Sociedade Carnavalesca Príncipe Coroado", no morro de Santo Antônio, que tinha como presidente o também trabalhador do cais do porto Perciliano da Silva; ${ }^{39}$ Horácio de Souza Moreira, além de sócio da "Resistência", também foi o vice-presidente do "Clube Carnavalesco Filhos do Castelo de Ouro", com sede na ladeira do Seminário, no Centro. ${ }^{40}$ Entre os

\footnotetext{
35 Diário Carioca, 27 fev. 1931. Citado por Moura (1995, p.89).

${ }^{36} \mathrm{Apesar}$ de alguns nomes serem bastante comuns, a probabilidade de se tratar das mesmas pessoas é bem grande, pois em alguns pedidos de licença consta a profissão dos membros da diretoria, o que nos informa que eram "trabalhadores do café", ou "trabalhadores do cais do porto".

${ }^{37}$ Apesar de ser um nome comum, com certeza trata-se do mesmo Antenor pois, segundo Rachel Valença, um certo Antenor dos Santos, trabalhador da estiva, era mineiro e dava jongo na rua Itaúba, na Serrinha. Essas informações (incluindo o endereço) batem com a ficha dele no Livro de Matrícula de Sócios do "Resistência". Consta que sua matrícula é de 1910. Cf.: Valença (1981).

${ }^{38} \mathrm{AN}-\mathrm{GIFI}-6 \mathrm{C}-135$.

${ }^{39} \mathrm{AN}-\mathrm{GIFI}-6 \mathrm{C}-367$ (Pacote 418 Caixa 5556).

${ }^{40} \mathrm{AN}$ - GIFI - IJ6 564.
} 
nomes do Livro de Sócios desse sindicato, foi encontrado ainda um Gastão de Souza que foi, em 1906, o presidente da "Sociedade Carnavalesca Rainha do Mar", no bairro da Glória. ${ }^{41}$

Entre os sócios fundadores da "União dos Estivadores”, foram encontrados vários nomes que constam na direção das associações de lazer espalhadas pela cidade. ${ }^{42}$ José Alves Pereira, por exemplo, em 1906 era o presidente do "Grupo Carnavalesco Flor do Castelo", com endereço na rua do Castelo, no $32 .{ }^{43}$ Nesse mesmo ano, o sócio Alfredo Nunes do Vale era o vice-presidente da "Grupo Carnavalesco Filhos da Cachoeira", com sede em São Cristóvão; ${ }^{44}$ João Antônio de Oliveira era, em 1912, o $2^{\circ}$ secretário do "Clube Dançante Familiar e Recreativo Os Faíscas", na rua do Areal, no $38 .{ }^{45}$ Em 1913, Manoel Pereira da Silva era o presidente do "Clube Carnavalesco Heróis do Brasil", no bairro de Campo Grande ${ }^{46}$ e Ricardo Antônio de Moraes dirigia, em 1915, o "Grupo Carnavalesco Cornetas de Madureira", no bairro de mesmo nome. ${ }^{47}$ Na rua Senador Pompeu, no 246, funcionava a "Sociedade Dançante Carnavalesca Reinado de Silva”, cujo presidente Arthur Maria de Araújo, assim como os outros, era sócio daquele sindicato. Próximo dali, em um sobrado na rua da Saúde, no 166, o estivador Manoel da Costa fazia as vezes de tesoureiro do "Grupo Carnavalesco Estrela de Ouro da Saúde". ${ }^{48}$ Procópio Augusto Andrade, além de estivador sindicalizado, era o presidente da "Sociedade Dançante Mimosos Pierrots", que funcionava na General Pedra, no 76 . Também encontramos como $2^{\circ}$ secretário do "Grupo Carnavalesco Filhos dos Teimosos do Engenho Velho", em 1906,49 um certo Joaquim Nunes, talvez o pernambucano Joaquim Januário Nunes, um dos sócios fundadores da "União".

Ao que parece, não era só de política que os membros dos sindicatos portuários viviam. Militantes políticos e membros de sindicatos também poderiam se organizar em torno de associações não sindicais, como as de cunho recreativo, indicando os diferentes níveis de articulação daqueles trabalhadores.

Os sócios das associações recreativas, como apontou Leonardo Afonso de Miranda Pereira, ao fazerem do lazer um motivo de união, mostravam ter ali um elemento de identidade, formando laços que eram expressos em momentos diversos (Pereira, 2002, p.427). Assim como os sócios daqueles sindicatos portuários, ao se reunirem para festejar o carnaval, organizar ranchos ou simplesmente se encontrarem em bailes e festas, mostram que os laços que os uniam iam além daqueles construídos durante o trabalho e nas assembleias

\footnotetext{
$\overline{{ }^{41} A N-G I F I-6 C-170}$ (Pacote 178 Caixa 5359).

${ }^{42} \mathrm{Ao}$ contrário daqueles encontrados no "Resistência", não podemos assegurar - especialmente nos casos de nomes muito comuns - que se trata das mesmas pessoas.

${ }^{43} \mathrm{AN}-\mathrm{GIFI}-6 \mathrm{C}-171$ (Pacote 179 Caixa 5360).

${ }^{44} \mathrm{AN}-\mathrm{GIFI}-6 \mathrm{C}-170$ (Pacote 178 Caixa 5359).

${ }^{45} \mathrm{~N}$ - Doc. Polícia - (Pacote 416 - Caixa 5553).

${ }^{46} \mathrm{AN}-\mathrm{GIFI}-6 \mathrm{C}-432$.

${ }^{47} \mathrm{AN}-1 \mathrm{~J} 6564$.

${ }^{48}$ Nos registros dos trabalhadores portuários da Casa de Detenção consta um Manoel da Costa com endereço na rua da Saúde, no 8. A "Estrela de Ouro da Saúde" no número 166 daquela mesma rua, aumentando as possibilidades de ser a mesma pessoa.

${ }^{49} \mathrm{AN}$ - GIFI - 6C - 170 (Pacote 178 Caixa 5359).
} 
sindicais. Se, por um lado eles se reuniam para discutir os rumos da greve, a jornada de trabalho ou o preço dos volumes das sacas de café que embarcavam diariamente no cais do porto, por outro também se reuniam para resolver o dia apropriado para sair o rancho, quando haveria baile na sede do clube recreativo e outras questões relativas ao seu lazer. E, nesses momentos, assim como no trabalho e no sindicato, eles também se reconheciam como fazendo parte de um mesmo grupo, com interesses semelhantes, se identificando como trabalhadores.

\section{Referências bibliográficas}

BATALHA, Claudio H. M.; SILVA, Fernando Teixeira da; FORTES, Alexandre (Org.). Culturas de classe: identidade e diversidade na formação do operariado. Campinas: Editora da Unicamp, 2004. CARVALHO, Lia de Aquino. Habitações populares. Rio de Janeiro: Secretaria Municipal de Cultura, 1995. (Coleção Biblioteca Carioca).

CERQUEIRA, Uassyr de. Entre sindicatos, clubes e botequins: identidades, associações e lazer dos trabalhadores paulistanos (1890-1920). Tese (Doutorado) - Universidade de Campinas. Campinas, 2008.

CHALHOUB, Sidney. Trabalho, Lar e Botequim: o cotidiano dos trabalhadores no Rio de Janeiro da belle èpoque. São Paulo: Brasiliense, 1986.

CUNHA, Maria Clementina Pereira. Ecos da folia: uma história social do Carnaval carioca entre 1880 e 1920. São Paulo: Companhia das Letras, 2001.

DECCA, Maria Auxiliadora Guzzo de. A vida fora das fábricas. Cotidiano operário em São Paulo (1920-1934). São Paulo: Paz e Terra. 1987.

JOÃO DO RIO. A alma encantadora das ruas. São Paulo: Companhia das Letras, 1997.

MOURA, Roberto, Tia Ciata e a pequena África no Rio de Janeiro. Rio de Janeiro: Secretaria Municipal de Cultura, 1995.

MUSEU DA IMAGEM E DO SOM (MIS). As vozes desassombradas do Museu. Rio de Janeiro: Secretaria de Educação e cultura, 1970.

OLIVEIRA, Maria Luiza Ferreira de. Entre a casa e o armazém. Relações sociais e experiência da urbanização, São Paulo, 1850-1900. São Paulo: Alameda, 2005.

PEREIRA, Leonardo Affonso de Miranda. E o Rio Dançou: Identidades e tensões nos clubes recreativos cariocas (1912-1922). In: CUNHA, Maria Clementina Pereira(Org.). Carnavais e outras f(r)estas: ensaios de história social da cultura. Campinas (SP): Ed. Da Unicamp; Cecult, 2002. SOIHET, Rachel. A subversão pelo riso: estudos sobre o carnaval carioca da Belle Ėpoque ao tempo de Vargas. Rio de Janeiro: Fundação Getulio Vargas, 1998.

THOMPSON, Edward P. A formação da classe operária inglesa. Rio de Janeiro: Paz e Terra, 1987. THOMPSON, Edward P. As peculiaridades dos ingleses e outros artigos. Organização de Antônio Luigi Negro e Sérgio Silva. Campinas: Editora da Unicamp. 2001.

VALENÇA, Rachel. Serra, Serrinha, Serrano: o império do samba. Rio de Janeiro: J. Olympio, 1981. 